\title{
ARQUEOLOGÍA DE UN JUEGO: LA CÉLULA. MICROCOSMOS DE VIDA ${ }^{1}$
}

\begin{abstract}
Alicia Gurdián-Fernández*
Resumen: En este artículo se argumenta que las denominadas nuevas tecnologías de comunicación e informática le presentan un reto a los sistemas educativos, en especial, a los de los países en vías de desarrollo. Puesto que desde ellos se puede replantear la formación de personas integrales no sólo capaces de utilizar dichas tecnologías y sus respectivos lenguajes, sino también de maximizar sus potencialidades como sujet@s sociales critic@s y creativ@s. Como resultado de una de las etapas del proyecto de investigación: la Red ProEducación: ProEd, de la Universidad de Costa Rica se produjo una innovación tecnológica aplicada a la educación: un disco compacto que contiene una aplicación educativa en formato de un juego de video: La Célula. Microcosmos de vida. Este juego, además de ser totalmente interactivo, le permite a @s estudiantes ir construyendo individualmente, y a su propio ritmo, los conocimientos más significativos, en una interfase más lúdica que los sistemas tradicionales de enseñanza, sobre la célula, propiciando en ell@s el proceso de "aprender disfrutando".
\end{abstract}

Palabras clave: TECNOLOGÍA EDUCATIVAV NTIC/ SISTEMAS EDUCATIVOS/ SOFTWARE EDUCATIVO/ JUEGOS/

"La vida... misterio de movimiento y cambios, enigmas de transformaciones infinitas, más allá de nuestros sentidos y nuestra imaginación existe un microcosmos que guarda los secretos de la vida. Lo he venido investigando durante años, pero ahora me vi forzado a ocultarme, sé que me han estado vigilando para apoderarse de los resultados y manipularlos sin ningún escrúpulo, como científico y ser humano no lo puedo permitir.

Antes de huir de la ciudad me vi obligado a esconder la información para mantenerla segura. Necesito tu ayuda para recuperarla y poder continuar con mis investigaciones, sé que no será fácil, alguien puede estar esperándote para aprovecharse de lo que puedas descubrir". ${ }^{2}$

\section{A manera de introducción... Red ProEducación}

Las críticas a las maneras tradicionales de enseñanza han adquirido mayor relevancia ante los requerimientos de una formación que permita afrontar la acelerada proliferación del

* Catedrática-Investigadora del Instituto de Investigaciones para el Mejoramiento de la Educación Costarricense, Facultad de Educación, Universidad de Costa Rica. Coordinadora del Proyecto ProEducación y Productora junto con Vanessa Fonseca González del juego computacional interactivo: La célula. Microcosmos de vida.agurdian@amnet.co.cr o agurdian@cariari.ucr.ac.cr

\footnotetext{
${ }^{1}$ Trabajo presentado en el IX Encuentro de Informática y Computación en Educación ENICE 2001, Universidad de Las Américas y Asociación Chilena de Informática y Computación en Educación. Santiago, Chile. 1-3 de agosto, 2001.

2 "La historia..." Juego Interactivo. La Célula. Microcosmos de vida. (2000). Derechos Reservados, Costa Rica: IIMEC-UCR, ISBN 9968-9930-0-5. Protegido por la OMPI.
} 
conocimiento. De hecho, la transferencia de conocimientos ha dejado de ser, poco a poco, el objeto prioritario de la educación; las y los estudiantes deberán aprender a adquirir información de acuerdo con sus necesidades, para luego transformarla en conocimiento e incorporarlo en su estructura cognitiva. Se vislumbra que el nuevo reto para los sistemas educativos es garantizar aprendizajes significativos, efectivos y transformadores que aporten además, decididamente al desarrollo de potencialidades individuales y colectivas, para que las personas puedan enfrentar, cotidianamente, la incertidumbre de un presente que acumula los problemas del pasado y las exigencias del futuro.

Bajo esta óptica, las nuevas tecnologías de comunicación e informática le presentan un reto a los sistemas educativos, en especial, a los de los países en vías de desarrollo. Desde ellos se puede replantear la formación de personas integrales, no sólo capaces de utilizar dichas tecnologías y sus respectivos lenguajes, sino también de maximizar sus potencialidades como sujet@s sociales, crític@s y creativ@s.

La Red ProEducación: ProEd, es el proyecto de investigación \# 724-98-365 del Instituto de Investigación para el Mejoramiento de la Educación Costarricense (IIMEC) de la Facultad de Educación de la Universidad de Costa Rica, concebido como una red educativa interactiva que tiene como meta habilitar computadores multimedia, "software" educativo y capacidad de comunicación por medio de una red. El equipo gestor de este proyecto estuvo integrado, inicialmente, por una educadora, una comunicadora, tres informáticos y un escultor.

Uno de los primeros hallazgos del proyecto fue determinar que, a pesar de la abundancia del "software" educativo y de su gran calidad técnica, éste se caracteriza, en general, por carecer de un marco filosófico-epistemológico que sustente la aproximación o estrategia metodológica que utilizan. Esto interfiere con la reestructuración activa de las percepciones, conceptos y esquemas que las usuarias y los usuarios incorporen en su estructura cognitiva. En otras palabras, la utilización de la tecnología por la tecnología ha descuidado la fundamentación de las propuestas de "software" educativo, y por lo tanto, el diseño conceptual de las mismas.

Como resultado de una de sus etapas, ProEd ofrece a la comunidad costarricense e internacional una innovación tecnológica aplicada a la educación. Esta innovación tecnológica consiste en un disco compacto que contiene una aplicación educativa en formato de un juego de video: La Célula. Microcosmos de vida. Este juego, además de ser totalmente interactivo, le permite a las y los estudiantes ir construyendo individualmente, y a su propio ritmo, los conocimientos más significativos sobre la célula, en una interfase más lúdica que los sistemas tradicionales de enseñanza, propiciando así el placer de "aprender disfrutando". 
El argumento del juego gira alrededor de un científico famoso a quien han amenazado con robarle información, producto de años de trabajo, sobre su último descubrimiento científico: la célula. Por esta razón, la o el usuario, deben ayudarle a recobrar sus hallazgos. Para ello, requieren resolver una serie de ejercicios y acertijos, así como descubrir mensajes o pistas que se localizan en diferentes escenarios: el laboratorio, la biblioteca, el café, la feria o parque de diversiones, el museo, el exploratorium y el parque.

El juego también ofrece en su barra de herramientas un mapa, entre otras opciones, para movilizarse y explorar los diferentes sitios de la ciudad. En el disco se introdujo una ayuda con locución, además de la ayuda impresa que aparece en el folleto que lo acompaña. La meta de este juego es recobrar tres cristales para devolverle al científico sus hallazgos y, al lograrlo, obtener una recompensa.

\section{Diseño: ¿En el país de las maravillas o mundo virtual?}

El juego, "La Célula. Microcosmos de vida", constituye un sistema con una estructura planificada, sistemática y predecible, con opciones predefinidas por sus productoras profesionales que asumieron funciones equivalentes a las de directoras y guionistas de una película.

La estructura propia de este juego es la "navegación" o trayectoria, que se inicia en el laboratorio e incluye una secuencia de desplazamientos con acertijos y ejercicios que la o el usuario deben controlar. Cierra con un viaje al interior de la célula, premio que se gana después de descubrir el tercer y último cristal.

El imperativo de los procesos adquiere gran importancia, de acuerdo con la perspectiva de los guiones técnico y artístico, porque el protagonismo de los acertijos, obstáculos o amenazas, está asentado en la ética/estética del diseño y de la imaginación, es decir, del exceso, ya sea de la velocidad, de la agilidad, de la fuerza o del suspenso, producto de la influencia del formato de los juegos de video.

La prioridad de estos procesos tiene su correspondencia lógica con los aspectos técnicos de este juego computacional interactivo que utiliza, por ejemplo, la animación limitada de carácter sonoro: verbal y musical, así como la navegación simulada, mientras lo restante es estático. Esta es una solución económica para producir la ilusión de desplazamiento virtual e invitar a la o el usuario a "entrar", "estar" y "moverse" en los diferentes escenarios para hacer uso de los libros, equipos, aparatos, carteles e información 
que se ofrece, tanto en el mismo disco compacto como ingresando a Internet a través de la computadora que se encuentra en la biblioteca.

El uso de "sprites"3 es una solución económica para producir la ilusión de movimiento, pues un desplazamiento consiste en mostrar un mismo "sprite" sucesivamente en diferentes lugares de la pantalla. Esta técnica, sumada a la animación limitada y a la utilización del video, acentúa la simulación de las trayectorias. Los escenarios diseñados, en consonancia con lo anterior, asemejan poseer un significado de realidad y un carácter lúdico que se ajusta a la audiencia a quien va dirigido el juego.

La filosofía del juego se transmite a través de la inmersión de la jugadora o del jugador dentro de él. En este sentido, la interactividad del juego permite la presencia del yo -de quien lo juega- dentro de éste, para localizar los tres cristales, a veces de forma muy gráfica y explícita; además, se puede experimentar con el cursor y "tocar" presionando las diferentes "zonas calientes". La jugadora o el jugador está físicamente fuera de la pantalla, pero vicariamente está en el interior del espacio o mundo ficticio de la actividad, situación, lugar o escenarios donde se desarrolla la trama propuesta en el juego; este es el espacio diegético ${ }^{4}$.

La jugadora o el jugador viven una ilusión de libertad en el seno de un laberinto diseñado por otras personas y con opciones, perfectamente predeterminadas, a pesar de que durante el juego el programa es percibido como una extensión orgánica de su conciencia. Esta impresión de ser libre dentro de una estructura impuesta por otra persona, y estar dentro de un laberinto emocionante, constituye uno de los mayores estímulos del juego.

La relación poder/distancia de las usuarias y los usuarios de La Célula Microcosmos de vida, permite no sólo crear el deseo o sensación de penetrar en el espacio virtual que ofrece la pantalla, sino que también, incide sobre la relación de poder entre el profesora o profesor y el estudiante. Podemos afirmar que la usuaria y el usuario intenta emular a Alicia en su acción de atravesar el espejo, lo que le permite una relación más libre con las actividades y los contenidos por aprender. Esto se logra mediante la imagen digital o infográfica y, sin

\footnotetext{
${ }^{3}$ Los "sprites" son elementos de la imagen, rígidamente caracterizados y almacenados, que se utilizan para producir la ilusión de movimiento mediante el desplazamiento, porque éste consiste en mostrar un mismo "sprite" sucesivamente.

${ }^{4}$ Toda narrativa ofrece dos aspectos: es al mismo tiempo una historia y un discurso.

Las palabras evocan un universo que en parte está hecho de palabras y en parte de actividades no verbales. Es decir, quien narra puede contarnos hechos o puede contarnos palabras. Desde Platón se viene distinguiendo entre mímesis (relato de palabras, es decir, relato de lo que dicen los personajes) y diégesis (o relato de "no palabras," es decir, narrar lo que hacen los personajes).
} 
reserva, potencia aún más la realidad virtual ${ }^{5}$ y su plasticidad para propiciar aprendizajes significativos y romper relaciones de poder verticales.

En síntesis, la imagen digital maximiza la imaginación mediante el poder de hacer real o auténtico aquello que se desea crear. La imagen digital se ha convertido en un gran crisol de efectos visuales, ya que posibilita la creación de imaginarios utilizando un teclado, una pantalla y una máquina. Se vislumbra una nueva antropología de lo visible, por lo que es urgente que emerja en el campo de la educación la figura del educador diseñador o educadora diseñadora con vocación artística, creatividad y gran imaginación.

La gran novedad educativa y cultural de la imagen digital radica en que es una tecnología para crear, para producir y para imaginar un mundo real en un espacio virtual.

\section{Constructivismo e intervención pedagógica}

Debido a la complejidad y multideterminación del fenómeno educativo, éste puede ser explicado desde otras ciencias. Desde esta perspectiva, de la psicología educativa, nos interesa utilizar la concepción constructivista del aprendizaje y la intervención pedagógica.

La concepción constructivista se alimenta de los aportes de diferentes corrientes psicológicas asociadas a la psicología cognoscitiva. De ellas, interesa destacar la teoría ausubeliana de la asimilación y el aprendizaje significativo, y la psicología sociocultural vigotskiana. Ambas corrientes comparten el principio de la importancia de la construcción - o reconstrucción - del aprendizaje por parte de la o el estudiante. Este es uno de los puntos de partida fundamentales para el diseño conceptual de este juego.

Según Carretero (1993:21), el constructivismo es:

La idea que mantiene que el individuo -tanto en los aspectos cognitivos y sociales del comportamiento como en los afectivos- no es un mero producto del ambiente ni un simple resultado de sus disposiciones internas, sino una construcción propia que se va produciendo día a día como resultado de la interacción entre esos dos factores. En consecuencia, según la posición constructivista, el conocimiento no es una copia fiel de la realidad, sino una construcción del ser humano. ${ }^{6}$

${ }^{5}$ El término realidad virtual constituye en sí mismo una paradoja pues está conformado por otros dos conceptos contradictorios y autoexcluyentes, algo no puede ser real y virtual a la vez. Hay quienes optan por denominarla mundo virtual o realidad artificial.

${ }^{6}$ Carretero, M. (1993). Constructivismo y Educación. Zaragoza, España: Edelvives. 
Este proceso de construcción, punto de partida para el diseño del juego, depende de: a) los conocimientos previos o la representación que se tiene de la información, actividad o ejercicio por resolver y b) la actividad, externa o interna, que la o el estudiante realice. Desde el enfoque constructivista, se rechaza la concepción de la o del estudiante como un simple receptor o reproductor de los saberes culturales y se acepta la idea de que el desarrollo es la acumulación de aprendizajes específicos. El sustento filosófico que subyace en estos planteamientos requiere que la escuela promueva tanto el doble proceso de socialización como el de individualización en las y los estudiantes, para que logren, de esta manera, construir su identidad en el marco de un contexto social e histórico determinado. Este juego requirió hacer uso de este sustento filosófico.

En consecuencia, la finalidad de la intervención pedagógica es estimular el desarrollo, en las y los estudiantes, de su propia capacidad para efectuar aprendizajes significativos en una amplia gama de situaciones y circunstancias, de forma tal que las y los estudiantes aprendan a aprender disfrutando. Por tanto, la función de quien participa en la producción de "software" educativo, es enseñar a pensar-comprender y a actuar sobre contenidos significativos ubicados en un contexto social e histórico específico, aspectos que guiaron la producción del juego "La célula. Microcosmos de vida".

Aprender un contenido quiere decir que la o el estudiante le atribuyen un significado a este por medio de la construcción de una representación mental, ya sea mediante imágenes, modelos, mapas, esquemas o proposiciones verbales como marco explicativo de dicho conocimiento. Construir nuevos significados conlleva un cambio en los esquemas de conocimiento que poseía el estudiante anteriormente, esto se sitúa en la teoría del aprendizaje significativo.

\section{Aprendizaje significativo}

Ausubel (1976) $)^{7}$ postula, en primer lugar, que el aprendizaje implica una reestructuración activa de las percepciones, ideas, conceptos y esquemas que la o el estudiante posee en su estructura cognitiva. En segundo lugar, concibe a quien aprende como una persona que procesa activamente la información, y afirma que el aprendizaje es sistemático y organizado porque es un fenómeno muy complejo que no se reduce a simples asociaciones memorísticas. En tercer lugar, propugna por un aprendizaje verbal significativo que permita el dominio de los

\footnotetext{
${ }^{7}$ Ausubel, D.P. (1976). Psicología educativa. México: Trillas.
} 
contenidos curriculares que se imparten en las instituciones educativas de nivel medio y superior.

De acuerdo con este autor, es importante diferenciar dos dimensiones del tipo de aprendizaje que ocurre en el "aula": la que se refiere a la forma en que se adquiere el conocimiento y la que se refiere a la forma en se incorpora ese conocimiento en la estructura cognitiva de quien está aprendiendo. En el contexto de la época moderna es válido afirmar que estas dos dimensiones también son transferibles a los aprendizajes que ocurren fuera del aula y que cotidianamente se adquieren a través de las TIC (Tecnologías de la Información y la Comunicación).

En la primera de dichas dimensiones se ubican dos tipos de aprendizaje: por percepción y por descubrimiento. En la segunda dimensión, se ubican otros dos: por repetición y por significación (o significativo). La interacción de estas dos dimensiones se expresa continuamente no sólo en las situaciones de aprendizaje escolar, sino también,, por ejemplo, en el "software" educativo, específicamente, por medio de la recepción repetitiva y, en algunos casos, por medio del descubrimiento repetitivo, pero no por medio ni de la recepción significativa ni del descubrimiento significativo.

Pertinente aclarar que estas cuatro situaciones forman parte de un sistema continuo, esto quiere decir que son interdependientemente dinámicas por lo que es errado concebirlas como compartimentos estanco. Todo lo contrario. Son posibilidades donde se entretejen la intervención pedagógica y la actividad cognoscente y afectiva de quien aprende, dinámica que se desarrolla en un ambiente particular que, no es necesariamente el aula. Sin olvidar, en primer lugar, que la intervención pedagógica se expresa mediante actividades intencionales, planificadas y sistemáticas; y en segundo lugar, que las condiciones para el logro del aprendizaje significativo se relacionan con:

- La motivación o actitud, la naturaleza de la estructura cognitiva y los conocimientos o experiencias previas de la o el estudiante. (Significado psicológico).

- La relacionabilidad no arbitraria, la relacionabilidad sustancial y la estructura y organización del contenido o material. (Significado lógico).

Interesa profundizar en este último punto, pues, para que el aprendizaje sea significativo debe reunir las siguientes características: la nueva información se debe relacionar de forma no arbitraria y sustancial con lo que la o el estudiante saben, de igual forma se debe tomar en consideración su disposición (actitud y motivación) por aprender y la naturaleza de los contenidos que se van a aprender. La relacionabilidad no arbitraria se refiere a que el contenido que se va aprender no es arbitrario en sí mismo y tiene suficiente intencionalidad, es 
decir, hay una manera de relacionarlo con las clases de ideas pertinentes y relevantes que los seres humanos somos capaces de aprender. La relacionabilidad sustancial se refiere a que si el contenido no es arbitrario, un mismo concepto puede expresarse de forma sinónima y seguir transmitiendo el mismo significado.

En síntesis, durante el aprendizaje significativo, el estudiante relaciona de manera no arbitraria y sustancial la nueva información con los conocimientos y experiencias previas y familiares que ya poseen en su estructura cognitiva (o de conocimientos).

El significado lógico se refiere al significado inherente que posee el contenido debido a su propia naturaleza y sólo puede convertirse en significado real o psicológico cuando el significado potencial se transforma en un nuevo significado dentro de un sujeto en particular.

De lo anterior, la necesidad e importancia de que la o el productor de un juego, comprendan los procesos motivacionales y afectivos subyacentes al aprendizaje de sus estudiantes, así como los procesos de desarrollo intelectual y las capacidades cognitivas de sus estudiantes en las diversas etapas de su ciclo de vida. Estos aspectos no se pueden obviar en la construcción de un mapa conceptual ni en la selección y organización de las actividades que se incorporarán en un juego, menos aún en el diseño conceptual de "software" educativo.

La construcción de significados involucra a la y a el estudiante en su totalidad; por lo tanto, esto obliga a ir más allá de los procesos cognitivos e introducir el sentido y la relevancia del aprendizaje escolar en un contexto particular, con el fin de subrayar el carácter experiencial que en buena lógica constructivista impregna el aprendizaje escolar.

\section{Diseño del prototipo}

5.1 Los siguientes supuestos son orientadores de las diferentes etapas de producción del juego.

I. Las críticas a las maneras tradicionales de enseñanza han adquirido mayor fuerza ante los requerimientos de una formación que permita afrontar:

- la revolución de las comunicaciones y

- la necesidad de garantizar aprendizajes relevantes que aporten al desarrollo de las potencialidades de las personas para enfrentar escenarios inéditos.

II. El "software" educativo en español, se caracteriza por la ausencia de un marco filosóficoepistemológico que sustente la aproximación metodológica que utiliza. La utilización de la tecnología por la tecnología ha descuidado el diseño conceptual del "software" educativo. Esto interfiere directamente con la reestructuración activa de las 
percepciones, conceptos y esquemas que las usuarias y los usuarios poseen en su estructura cognitiva.

III. La oportunidad que Costa Rica deje de consumir pasivamente productos computacionales educativos, y se convierta, eventualmente, en productora y competidora en el ámbito internacional.

IV. Brindar un medio interactivo intenso y agradable capaz de capturar la imaginación y crear un ambiente de aprendizaje multisensorial.

V. Optimizar el deseo de aprender por parte de las y los estudiantes.

VI. El juego se puede concebir como un factor sustantivo para el mejoramiento de la calidad de la educación.

VII. Introducir aplicaciones multimedia que promuevan aprendizajes significativos.

VIII. La necesidad de que las y los jóvenes se responsabilicen por su propio aprendizaje.

IX. Exponer a las y los estudiantes a la ventaja educativa que les ofrece navegar en el espacio cibernético.

X. Promover cambios actitudinales positivos que propicien el éxito escolar mediante "aprender disfrutando".

5.2 Otros aspectos fundamentales por considerar en el diseño exitoso, de un juego con aplicaciones multimedia, es que debe tener una apariencia y forma estéticamente agradables y atractivas, pues así podrá mantenerse el interés de la audiencia para la que es producido. Además, si el producto tiene fines educativos, hay que sumarle todo un conjunto de experiencias pedagógicas, comunicativas, multisensoriales y de psicología educativa, entre otras.

Determinar, por ejemplo, las estrategias de aprendizaje más apropiadas para el mapa conceptual seleccionado requiere de una planificación rigurosa, un control preciso de la ejecución y de los procesos de evaluación formativa continuos.

Ahora bien, es imprescindible contar, en primer lugar, con un equipo multidisciplinario ojalá interdisciplinario - que sea realmente capaz de trabajar en equipo.

La experiencia del IIMEC en este campo, ha sido integrar equipos compuestos por una o un: director del proyecto, pedagogo, comunicador, guionista, diseñador gráfico, programador, técnico de sonido, editor de video y fotógrafo. No obstante, algunos de los integrantes del equipo no estarán presentes durante todo el desarrollo del proyecto, como es el caso de los técnicos de fotografía, video y sonido. 
El equipo que produjo este juego estuvo a cargo de las actividades que se enuncian a continuación, que, de hecho, no son exhaustivas:

1. Análisis y evaluación de las herramientas de "authoring systems" o sistemas de autor más utilizadas para los ambientes PC.

2. Selección del tema por desarrollar.

3. Elaboración de diversos mapas conceptuales para determinar la secuencia adecuada para propiciar aprendizajes significativos.

4. Selección del mapa conceptual apropiado.

5. Definición del enfoque, profundidad y secuencia para el tratamiento de los contenidos y procesos.

6. Diseño de los guiones artístico, pedagógico, científico, técnico y creativo del prototipo.

7. Análisis y validación de los diferentes guiones.

8. Análisis de la relación sustancial entre la nueva información y el conocimiento previo de las y los estudiantes.

9. Evaluación del significado lógico del contenido y material.

10. Confrontación de los guiones y los recursos existentes.

11. Identificación de los recursos institucionales disponibles: videos, laboratorio de sonido, equipos, laboratorios científicos, entre otros.

12. Integración de conceptos multidisciplinarios e interdisciplinarios en ambientes cognoscitivos multisensoriales.

13. Diseño de la interactividad de los ambientes cognoscitivos-afectivos propuestos.

14. Diseño de los diferentes prototipos que se produjeron.

15. Programación y evaluación de las diferentes pruebas realizadas.

A partir de lo expuesto es posible sugerir una serie de principios educativos que se desprenden de la producción, aplicación y evaluación de este juego computacional interactivo.

1. El aprendizaje se facilita cuando los contenidos se presentan en forma estructurada y siguiendo una secuencia lógica-psicológica apropiada.

2. Los contenidos aprendidos significativamente son más estables y permiten transferir lo aprendido.

3. Una de las tareas principales de la productora o el productor de un juego, es estimular la motivación y participación activa de las y los usuarios, buscando las 
estrategias para aumentar el significado potencial de los materiales y medios usados.

4. El utilizar mapas conceptuales para la producción de juegos educativos no sólo garantiza el aprendizaje significativo, sino que también facilita el proceso de validación de los guiones que se crean.

5. El mapa conceptual es fundamental para la selección de estrategias y ejercicios de aprendizaje.

6. La motivación de las y los usuarios del juego es un proceso exclusivamente endógeno e intrapersonal, en el cual, intervienen poco los procesos interpersonales, pero sobre el que sí pueden incidir positivamente, por ejemplo, el diseño gráfico y los efectos especiales.

7. La motivación escolar es un proceso básicamente afectivo y el juego incentiva este proceso.

8. El papel de la motivación en el logro del aprendizaje significativo está íntimamente ligado con la necesidad de inducir el interés y el esfuerzo necesarios, por lo que es inherente al juego ofrecer la dirección y guía pertinentes para alcanzarlos.

9. En la producción de un juego educativo como este es indispensable manejar las variables que definen el contexto de la actividad a saber: contenidos, recursos, tareas, patrones de interacción, experiencia y evaluación, entre otras.

10. La producción de un juego educativo debe cumplir ciertos requisitos básicos para lograr que se construyan los aprendizajes significativos, como que el estudiante sea capacaz de relacionar de manera no arbitraria y sustancial los nuevos contenidos con los conocimientos y experiencias previas que poseen en su estructura cognitiva, así como que posean la disposición por aprender significativamente y que los contenidos de aprendizaje tengan un significado potencial y lógico.

11. La motivación condiciona el interés y esfuerzo que manifiestan los estudiantes en sus actividades y determina el aprendizaje resultante, por lo que un requisito para la producción de un juego es el conocimiento y manejo de la motivación escolar.

12. La producción de un juego educativo de la índole que nos ocupa, no puede soslayar que la investigación sobre las estructuras y procesos cognitivos realizada desde la década de los sesenta hasta la de los ochenta inclusive, ayudó de forma significativa a forjar el marco conceptual del enfoque cognitivo contemporáneo. Marco conceptual que se sustentó en las teorías de la información, la 
psicolingüística, la simulación por computadora y la inteligencia artificial, para así proponer nuevas conceptualizaciones sobre la representación y naturaleza del conocimiento, la memoria, la solución de problemas, el significado y la comprensión y producción del lenguaje.

13. Las ayudas que se le proporcionan a la estudiante o al estudiante, en el caso de la aproximación impuesta, pretenden facilitar intencionalmente un procesamiento profundo de la nueva información y son planeadas, en este caso por la diseñadora o el diseñador de un juego o de un "software" educativo. Dos líneas de trabajo iniciadas en la década de los setenta son: la aproximación impuesta que consiste en realizar modificaciones en la estructura del material de aprendizaje, y la aproximación inducida, que se aboca a entrenar a las y los aprendices en el manejo directo de los procedimientos que les permitan aprender con éxito y de manera autónoma. (Levin, 1971) (Shuell, 1988)

\section{Reflexión-conclusiones}

1. La educación, entendida como actividad mediante la cual se produce y distribuye el conocimiento, asume una importancia histórica inédita no sólo desde el punto de vista político-social, sino también desde la selección de los contenidos de la socialización y su impacto en la apropiación inteligente del espacio cibernético frente a la hipótesis que sustenta la emergencia de la sociedad del conocimiento.

2. Las computadoras han pasado a ocupar un lugar prioritario en las actividades del mundo moderno, puerta que se abre, aún con mayores posibilidades e implicaciones, con proyectos de inteligencia artificial. En consecuencia, es de vital importancia que las y los educadores incorporen críticamente este recurso tecnológico en su práctica pedagógica, ya que como bien se ha dicho, las computadoras pueden solucionar problemas, pero necesitan del ser humano para descubrir tales soluciones.

3. El amplio horizonte que se vislumbra con la sociedad global, en términos de integración y fragmentación, abre nuevas posibilidades para interpretar el presente, así como para releer el pasado e imaginar el futuro de la educación. Este horizonte también invita a la reflexión, imaginación e interpretación de realidades no codificadas, y también arriesgarnos a adivinar sorpresas inimaginadas en todos los campos, donde la educación, sin duda, no será la excepción. 
4. La amplia expansión de redes electrónicas no implica concentración de conciencias y voluntades; pero, sin lugar a dudas, las consecuencias de esta expansión técnica, material y simbólica de las tecnologías de la información y la comunicación (TIC), ${ }^{8}$ marcan de manera decisiva la vida contemporánea. A partir de éstas, se adivina la aparición y configuración de nuevas disciplinas, nuevas técnicas del saber, del aprender, del hacer, del sentir, de una pragmática del lenguaje, de géneros narrativos y de modos de relatar. También representa una transformación de las relaciones interpersonales, nuevas formas de percepción del tiempo y del espacio y, a la vez, una redistribución diferente de los espacios de la cotidianidad.

5. En la época actual, vivimos dentro de una cultura mediática, a partir de la cual se ha empezado a construir una cultura cibernética: un verdadero sistema neurológico mundial que indiscutiblemente repercute en nuestra manera de ser, aprender, sentir y actuar, lo admitamos o no. ¿Cómo se relaciona o incide esto en nuestra práctica profesional? ¿Cómo utilizar inteligente y críticamente todo este potencial?

6. Las sociedades actuales tienden a ser, en mayor o menor medida, "sociedades del conocimiento" en las que el desarrollo de las TIC puede crear un entorno cultural y educativo capaz de diversificar no sólo las fuentes del saber y el conocimiento, sino también de propiciar su redistribución. Sin embargo, esto excede el marco de su simple utilización pedagógica y requiere una reflexión amplia y colectiva sobre el acceso al conocimiento.

7. Es prioritario ubicar la utilización de las TIC en un contexto social, económico y político apropiados, puesto que es indiscutible que éstas crean nuevas formas de socialización e incluso, nuevas definiciones de la identidad individual y colectiva. ¿Cómo utilizar el espacio cibernético y las diversas aplicaciones tecnológicas y comunicativas en educación para asegurarnos una re-distribución justa y solidaria del conocimiento?

8. A las educadoras y educadores les corresponde crear los mecanismos que les permitan, a los diferentes actores sociales, tomar distancia con respecto a una sociedad mediática caracterizada tanto por lo efímero como por lo instantáneo. Les corresponde, de igual forma, aportar los modos de socialización indispensables para una apropiación sana de las TIC y sentar las bases para el ejercicio de una ciudadanía apropiada a las exigencias de nuestra época.

9. La utilización y aplicación de las TIC en los diferentes procesos educativos, requiere, por un lado, no sólo de un cambio de paradigma sino también de una revolución pedagógica cuya

\footnotetext{
${ }^{8}$ Las siglas TIC hacen referencia a las tecnologías de la información y la comunicación.
} 
base no sólo sea de índole económica, sino también cultural, social y política. De igual forma, se requiere de una profunda transformación de los programas de formación de docentes, ya que la introducción de las TIC lleva implícita una finalidad y otra concepción de mundo, de sociedad, de ser humano y del conocimiento y su adquisición. Concepciones diametralmente opuestas a las que han caracterizado los programas tradicionales aplicados en la formación de educadores.

10. La utilización de las TIC en el campo educativo formal e informal representa una transformación al menos en:

- los modelos de pensamiento y en la estructura del conocimiento

- los procesos de enseñanza y aprendizaje;

- la re-estructuración de las formas tradicionales de organización, división y especialización del conocimiento;

- la promoción de un aprendizaje sincrónico hacia uno asincrónico y no lineal;

- las técnicas pedagógicas y didácticas que propician los cambios en las nuevas formas de apropiación del conocimiento;

- la forma para seleccionar, organizar y relacionar críticamente la información;

- la actualización y formación de docentes.

- las formas de circulación del conocimiento entre la educación formal e informal; y

- la diversificación y el mejoramiento de la educación a distancia.

11. El riesgo principal consiste, no obstante, en la creación de nuevas rupturas y desequilibrios, ya sea entre las distintas sociedades entre las más ricas y las más pobres o dentro de cada sociedad en particular, porque se crean desigualdades entre quienes tienen acceso y dominan las nuevas tecnologías informáticas y quienes no tienen aún esa posibilidad.

Finalizo con una cita que tiene el propósito de invitarles a atravesar el espejo y... adentrarse en la era de la imaginación:

Es posible pensar que con la interactividad penetrante de Internet, las computadoras y lo programas de computación cada vez más eficientes, la era de la información puede cambiar rápidamente a la era de la imaginación, un mundo en el que cualquier 
cosa que imaginemos puede ser rápidamente simulada y compartida en un mundo global a través de las tecnologías digitales. ${ }^{9}$

\section{Referencias}

Ausubel, D.P. (1976) Psicología Educativa. México: Trillas.

Battro, A. M. y Denham, P..J. (1997) La Educación Digital. Argentina: Emecé. 1997.

Brauner, J. y Bickmann. (1996) La sociedad Multimedia. Barcelona: Editorial: Gedisa. 1996.

Cañas, A. J. K. M. Ford, P. J. Hayes, T. Reichherzer, N. Suri, J. Coffey, R. Carff, G. Hill. (1997). Colaboración en la Construcción de Conocimiento Mediante Mapas Conceptuales. Memoria del VIII Congreso Internacional sobre Tecnología y Educación a Distancia, San José, Costa Rica, pp. XXV- XLII.

Carretero, M. (1993). Constructivismo y Educación. Zaragoza, España: Edelvives.

Gallego, D. J. y Alonso, C.M. (1997) Multimedia. Madrid: Universidad Nacional de Educación a Distancia.

Gurdián-Fernández, A. y Fonseca, V. (2000) Juego Interactivo. La Célula. Microcosmos de vida. Derechos Reservados, Costa Rica: IIMEC-UCR, ISBN 9968-9930-0-5. Protegido por la OMPI. Formato Disco Compacto.

Gurdián-Fernández, A. (2001) Aporte de las Nuevas Tecnologías de la Información y la Comunicación a los perfiles y planes inéditos de educación permanente de formadoras y formadores. Conferencia para el Proyecto: Apoyo al Mejoramiento de la Formación Inicial de Docentes en Educación Primaria CECC. CENADI (Centro Nacional de Didáctica). Ministerio de Educación Pública de Costa Rica. Marzo, 2001, $\mathrm{p}, 5$.

Gurdián-Fernández, A. (2001) Arqueología de un juego. Trabajo presentado en el IX Encuentro de Informática y Computación en Educación ENICE 2001, Universidad de Las Américas y Asociación Chilena de Informática y Computación en Educación. Santiago, Chile. 1-3 de Agosto, 2001.

Novak, J.D. y Gowin, D.B. Aprendiendo a aprender. Barcelona: Martínez Roca. 1988.

Raskin, J, (2001) DISEÑO DE SISTEMAS INTERACTIVOS. La importancia de nuestra relación con las computadoras., México: Ed. Pearson Educación.

Scardamalia, M. \& C. Bereiter. (1993). Technologies for Knowledge-Building Discourse, Communications of the ACM, vol 36, 37-41.

\footnotetext{
${ }^{9}$ Gurdián-Fernández, A. (2001) "Aporte de las Nuevas Tecnologías de la Información y la Comunicación a los perfiles y planes inéditos de educación permanente de formadoras y formadores". Conferencia para el Proyecto: Apoyo al Mejoramiento de la Formación Inicial de Docentes en Educación Primaria CECC. CENADI (Centro Nacional de Didáctica). Ministerio de Educación Pública de Costa Rica. Marzo, 2001, p,5.
} 
Valzacchi, J.R. (1998) Internet y Educación. Aprendiendo y enseñando en los espacios virtuales. Argentina: Ediciones Horizonte- Informática educativa. 


\section{ANEXO-Ficha Técnica \\ Juego Computacional Interactivo}

1. Nombre: La Célula. Microcosmos de vida.

\section{Concepto y descripción de la innovación}

2.1 Naturaleza: Un disco compacto

2.2 Descripción: Juego computacional interactivo sobre la célula

\subsection{Elementos innovadores:}

Uso de lenguajes de multimedia, recursos audiovisuales y tecnologías de la comunicación, en un formato virtual, fundamentado en una concepción constructivista del aprendizaje basada en el juego, la exploración y la indagación. Lo anterior se eligió como parte de una concepción pedagógica lúdica de un ambiente de aprendizaje con recurso informático.

\section{Argumento o trama:}

Un científico famoso se ve amenazado por personas inescrupulosas, por lo que debe esconder toda la información, producto de años de trabajo, sobre su último descubrimiento: La célula. El usuario del juego debe ayudarle a recobrar sus hallazgos. Para ello, se requiere resolver una serie de ejercicios y acertijos, así como descubrir mensajes y pistas en diferentes escenarios, como el laboratorio, la biblioteca, el café, el parque de diversiones, el museo, el exploratorium y un parque, esto con el fin de que puedan localizar tres cristales y devolverle al científico sus hallazgos.

\section{Síntesis del programa donde se aplica la innovación}

Se desarrollaron las distintas herramientas de acceso multimedial: botones, ventanas de presentación, fondos y secuencias de presentación. De igual forma se integraron los llamados programas externos que facilitan la modularidad del diseño. También se elaboraron los programas suplementarios de secuencias de imágenes (simulación de movimientos), y se facilitó el programa NetScape para tener acceso a Internet y Quick Time, para poder ver los videos.

El sistema puede dialogar con productos de terceros como Netscape y dispone de bases de datos locales y remotas, también puede acceder a bases de datos en la Red. 
El prototipo es funcional localmente y se accesa por íconos, por lo que se da prioridad a la presentación visual complementada con sonido y finalmente con texto. Tiene un pequeño componente de simulación: viaje al interior de la célula.

Sus características de desarrollo constan de: un archivo ejecutable EXE (1.97 MB), corre bajo Windows 95 y contiene las características de multi-tarea e integración OLE. Consta de 300 líneas de código de 4ta generación en scripts multimedia, así como de clips de video (de unos 30 segundos cada uno) consumiendo unos $113 \mathrm{MB}$. En imágenes estáticas tiene alrededor de $20 \mathrm{MB}$. En clips de sonido posee $100 \mathrm{MB}$. En archivos de fondo, grafismo y definición de botones tiene $10 \mathrm{MB}$. En texto posee unos $10 \mathrm{MB}$.

El prototipo base de desarrollo fue elaborado pensando en un sistema multisensocial de indagación y documentación, dirigido a estudiantes del III Ciclo de la Educación General Básica, de la Educación Diversificada y de la Educación Técnica.

\section{5. "Software" utilizados para diseño y producción}

Diseño: El "software" que se usó, principalmente para el diseño de los gráficos y escenarios, fue Adobe Photoshop, para la elaboración de los íconos, botones, textos y punteros, se utilizaron las librerías incluidas dentro de Director de Macromedia, así como con algunas imágenes digitalizadas por medio de scanner.

Producción: La producción del programa fue elaborada con Director de Macromedia, una herramienta que permite utilizar e integrar audio, video, gráficos, íconos y cromos, además de contar con un potente lenguaje de programación (lingo) que es el que le permite al programa interactuar con el usuario por medio de comandos.

Audio: El audio (locución) fue elaborado en un estudio de grabación profesional de la Escuela de Ciencias de la Comunicación Colectiva de la Universidad de Costa Rica (CEPROAV), los sonidos de botones, ambiente y música, fueron controlados principalmente por medio del lenguaje lingo de Macromedia.

\section{Valor y contenido tecnológicos de la aplicación}

El juego interactivo se desarrolla temáticamente en un ámbito de la ciencia básica: la biología, y específicamente, sobre el tema de la célula, su estructura y función. Este es un tema fundamental en los programas curriculares del III Ciclo de la Educación General Básica, de la Educación Diversificada y de la Educación Técnica; y no se cuenta en el mercado con una herramienta interactiva y multimedial con características constructivistas para propiciar distintos procesos de aprendizaje mediante la tecnología aplicada al tema ya mencionado. 
Se realiza en el Instituto de Investigación para el Mejoramiento de la Educación Costarricense de la Facultad de Educación de la Universidad de Costa Rica con el apoyo de personal especializado de esta institución; así como con los recursos de imágenes y videos desarrollados en distintos centros de investigación de la universidad.

Además, se dirige a un sector educativo considerado de atención prioritaria en los procesos de enseñanza-aprendizaje. El juego es una herramienta educativa que dará apoyo a dichos procesos; así como a la cobertura de necesidades en la formación de las y los estudiantes y de las y los profesores de enseñanza media.

El diseño conceptual del juego mediante la utilización de recursos de multimedia y herramientas de comunicación, se convierte en un medio lúdico e innovador para el aprendizaje.

\section{Grado de aplicación realizada y aplicación potencial}

El prototipo se validó en forma dinámica por medio de las y los estudiantes del Liceo Laboratorio Emma Gamboa de la Universidad de Costa Rica, y a través del juicio de expertos de la Facultad de Educación, de la Escuela de Ciencias de la Computación e Informática, de la Escuela de Biología, del Departamento de Artes Gráficas de la Facultad de Bellas Artes y de la Escuela de Ciencias de la Comunicación Colectiva de la Universidad de Costa Rica.

Además, en Fercómputo, actividad organizada por la Vicerrectoría de investigación de la Universidad de Costa Rica, se consideró como un medio óptimo para valorar su grado de aceptación popular.

\section{Población a la cual está dirigido}

La aplicación potencial se dirige a estudiantes y docentes del III Ciclo de la Educación General Básica, de la Educación Diversificada y de la Educación Técnica en el ámbito público y privado; así como a los padres de familia.

\section{Impacto de la innovación en la modernización, eficacia y productividad de la empresa}

El juego interactivo promueve un concepto de educación virtual e interactiva para el desarrollo de procesos de enseñanza-aprendizaje. 


\section{Empleo de las tecnologías de la información en los procesos innovadores}

Se cumple con el empleo de las tecnologías de la información en los procesos innovadores de la educación. El sistema no sólo dispone de bases de datos locales y remotas, sino que a través de la red, puede extenderse a bases de datos en la Red.

\section{Autoras de la innovación y derechos de autoría}

Alicia Gurdián Fernández, Ph. D. y Vanessa Fonseca González , M. Sc., quienes conservan los derechos de autoría.

Nacionalidad: Costarricenses

Dirección: IIMEC-UCR

Tel. (506) 207-5635

Fax. (506) 207-4679

E-mail agurdian@cariari.ucr.ac.cr

El juego interactivo La Célula. Microcosmos de vida está registrado y protegido por la OMPI. EI ISBN del juego es 9968-9939-0-5. 